\title{
Epidermal Permeability Barrier Recovery Is Delayed in Vitiligo-Involved Sites
}

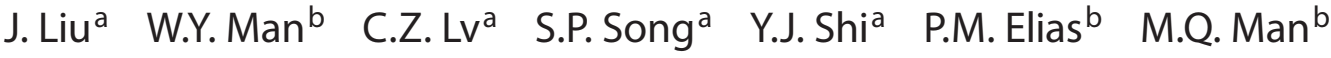 \\ ${ }^{a}$ Dalian Skin Disease Hospital, Dalian, The People's Republic of China; ${ }^{b}$ Department of Dermatology, University of \\ California, San Francisco, Calif., USA
}

\section{Key Words}

Vitiligo $\cdot$ Stratum corneum $\cdot$ Barrier function $\cdot$ Hydration

\begin{abstract}
Background/Objectives: Prior studies have demonstrated that both the skin surface $\mathrm{pH}$ and epidermal permeability barrier function vary with skin pigmentation types. Although melanin deficiency is the main feature of vitiligo, alterations in cutaneous biophysical properties in vitiligo have not yet been well defined. In the present study, stratum corneum (SC) hydration, the skin surface $\mathrm{pH}$ and epidermal permeability barrier function in vitiligo were evaluated. Methods: A total of 30 volunteers with vitiligo comprising 19 males and 11 females aged 13-51 years (mean age: $27.91 \pm 2.06$ years) were enrolled in this study. The skin surface $\mathrm{pH}, \mathrm{SC}$ hydration, melanin/erythema index and transepidermal water loss (TEWL) were measured by respective probes connected to a Courage-Khazaka MPA5. SC integrity was determined by measuring the TEWL following each D-Squame application. The barrier recovery rate was assessed at $5 \mathrm{~h}$ following barrier disruption by repeated tape stripping. Results: In addition to SC hydration, both melanin and erythema index were significantly lower in vitiligo lesions than in contralateral, nonlesional sites, while no difference in skin surface $\mathrm{pH}$ between vitiligo-involved and uninvolved areas was observed. In addition, neither the basal TEWL nor SC integrity in the involved areas differed significantly from that in the unin-
\end{abstract}

volved areas. However, barrier recovery in vitiligo-involved sites was significantly delayed in comparison with uninvolved sites (40.83 $\pm 5.39 \%$ vs. $58.30 \pm 4.71 \% ; t=2.441 ; p<$ 0.02). Conclusion: Barrier recovery following tape stripping of the SC is delayed in vitiligo. Therefore, improvement in epidermal permeability barrier function may be an important unrecognized factor to be considered in treating patients with vitiligo.

Copyright $\odot 2010$ S. Karger AG, Basel

\section{Introduction}

Skin pigmentation is primarily determined by the quantity of melanin [1], while multiple cutaneous functions are associated with skin pigmentation. For example, darker skin is less susceptible to Candida albicans infection [2]. In addition, following sodium lauryl sulfate treatment, darker skin is more sensitive to stinging sensation and displays a lesser increase in transepidermal water loss (TEWL) $[3,4]$. Moreover, there is a significant difference in the transcutaneous penetration of nicotinates between highly and lightly pigmented skin [5]. Furthermore, the severity of photodamage differs between highly and lightly pigmented skin [6], and the onset of skin aging is delayed in darker skin compared with lighter skin [7]. In addition, lighter skin becomes dryer than darker skin upon sun exposure [8], while the skin electric

\section{KARGER}

() 2010 S. Karger AG, Basel

Fax +41613061234 E-Mail karger@karger.ch www.karger.com www.karger.com/spp
Mao-Qiang Man, MD

Dermatology Service (190)

4150 Clement Street

San Francisco, CA 94121 (USA)

Tel. +1 415750 2091, Fax +1 415750 2106, E-Mail mqman@ hotmail.com 
Table 1. Characteristics of subjects

\begin{tabular}{llllcl}
\hline & \multirow{2}{*}{ Number } & Age, years & \multicolumn{3}{l}{ Involved sites, $\mathrm{n}$} \\
\cline { 4 - 6 } & & & limbs & trunk & others \\
\hline Female & 11 & $36.82 \pm 3.51$ & 3 & 7 & 1 \\
Male & 19 & $22.79 \pm 1.68$ & 10 & 8 & 1 \\
Total & 30 & $27.90 \pm 2.06$ & 13 & 15 & 2 \\
\hline
\end{tabular}

Values denote means \pm SEM unless stated otherwise.

resistance is higher in darker skin, too [9]. However, regarding the epidermal permeability barrier function in darker versus lighter skin, results are inconclusive. Some studies have shown that both basal TEWL and percent increase in TEWL are higher in darker skin following tape stripping [10-12]. In contrast, Singh et al. [13] reported that the basal TEWL was lower in darker skin. However, Reed et al. [14] reported that the basal TEWL in darker skin did not differ from that in lighter skin, but rather that stratum corneum (SC) integrity was significantly lower in lighter skin than in darker skin. Interestingly, barrier recovery is reportedly faster in darker skin as compared with lighter skin [14]. Although the basal skin surface $\mathrm{pH}$ is higher in black Africans than in Caucasians [15], it is significantly lower in darker-skinned individuals following tape stripping [12]. Nevertheless, these data all indicate that cutaneous functions vary with pigmentation.

Vitiligo is generally viewed as an autoimmune disorder. In support of this, histological studies have revealed increased cutaneous lymphocyte and macrophage infiltration in vitiligo-involved sites [16, 17], while helper T cells are decreased in patients with vitiligo $[18,19]$. Moreover, cytokines such as interleukin (IL)-6 and tumor necrosis factor (TNF)- $\alpha$ are increased in both vitiligo-involved skin sites and patients' serum [20-22]. Accordingly, immunosuppressors such as tacrolimus improve vitiligo [23-25], and imiquimod, an immunostimulator, could induce vitiligo [26-29]. Vitiligo is clinically featured by depigmentation and characterized by melanin deficiency [30]. Although the primary function of melanin is to protect the skin from UV damage [31-33], melanin also plays an important role in regulating multiple cutaneous functions. Firstly, melanin participates in the regulation of cutaneous immunity. For instance, synthetic melanin suppressed the production of TNF, IL-1 $\beta$, IL- 6 and IL-10 by lipopolysaccharide-stimulated monocytes [34]. In normal human monocytes, herbal melanin in- duces TNF- $\alpha$, IL- 6 and vascular endothelial growth factor (VEGF) mRNA expression [35]. Melanin also exhibits an antiviral activity in human lymphoblastoid cells [3638]. Secondly, sodium/hydrogen $\left(\mathrm{Na}^{+} / \mathrm{H}^{+}\right)$exchangers, key regulators of $\mathrm{pH}$ [39], are expressed on melanocytes and colocalize with melanosomes; melanosomes are also acidic [40,41]. Recent studies have demonstrated that the skin surface $\mathrm{pH}$ is lower in darker- than in lighter-skinned individuals [42]. Thirdly, alterations in keratinocyte proliferation have been observed in vitiligo. Keratinocytes from involved vitiligo skin have a shorter life span [43], while decreased levels of stem cell factor and increased apoptosis were observed in keratinocytes from vitiligo $[44,45]$. Furthermore, the SC is thicker in vitiligo-involved sites than that in uninvolved sites [46]. These noted changes in skin surface $\mathrm{pH}$, cytokine levels, SC thickness, keratinocyte proliferation and cytokine expression all have a significant impact on cutaneous biophysical properties such as epidermal permeability barrier function and SC integrity $[14,47-53]$. However, the changes in skin biophysical properties including epidermal permeability barrier function in vitiligo remain largely unknown.

In the present study, the skin surface $\mathrm{pH}$, SC hydration and epidermal permeability barrier function are assessed in vitiligo-involved and contralateral (uninvolved) skin.

\section{Materials and Methods}

\section{Subjects}

A total of 30 Chinese volunteers with stable vitiligo vulgaris, 19 males and 11 females aged 13-51 years, were enrolled in this study (table 1). Previous studies showed that skin response to UV radiation is influenced by skin pigmentation [54]. To eliminate any UV-induced changes in SC function in vitiligo-involved and uninvolved sites, only patients with vitiligo in non-sun-exposed sites were enrolled in the present study. All subjects were new patients with skin types III or IV (Fitzpatrick classification), and were without any topical or systemic medication for vitiligo. Their vitiligo was diagnosed by a vitiligo specialist at the vitiligo clinic of the Dalian Skin Disease Hospital, PR China. A clinical examination showed no sign of inflammation in both lesions and contralateral uninvolved sites. No skin care products had been applied to the measured sites $24 \mathrm{~h}$ prior to the measurements, and the measured sites had not been washed with soaps or surfactants for at least $2 \mathrm{~h}$ prior to the study.

\section{Measured Sites and Methods}

The basal TEWL, skin surface $\mathrm{pH}$, capacitance and melanin/ erythema were measured on both vitiligo-involved and contralateral uninvolved sites by respective probes connected to a Courage-Khazaka MPA5 (Courage Khazaka electronic GmbH, Köln, Germany) [55]. The skin surface $\mathrm{pH}$ was also measured by a 


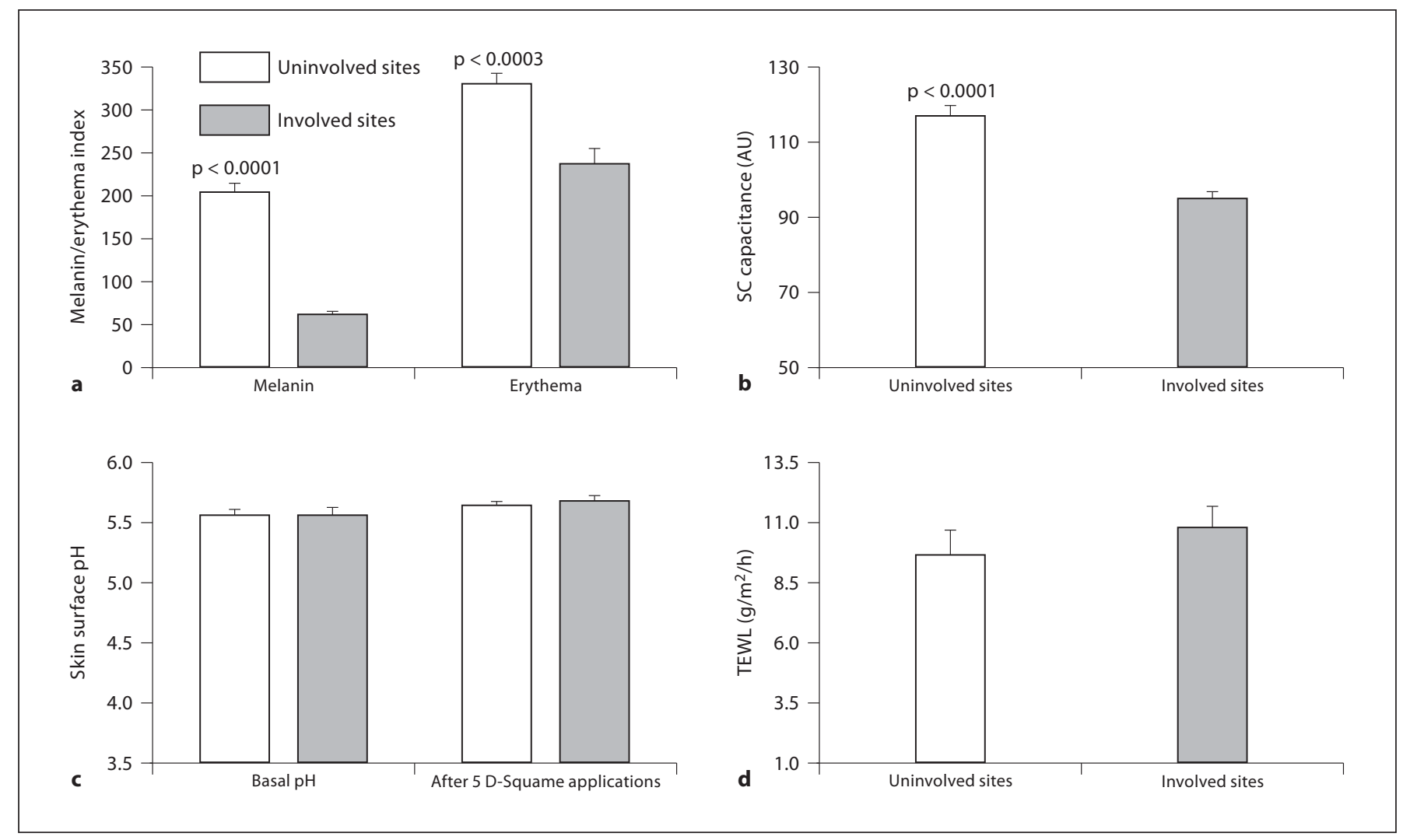

Fig. 1. Comparison of basal SC properties between vitiligo-involved and uninvolved sites. The SC properties were measured as described in the Materials and Methods section. The unpaired two-tailed Student t test with Welch's correction was used to determine the significance between vitiligo-involved and uninvolved sites. The paired two-tailed Student $t$ test was used to determine the significance in skin surface $\mathrm{pH}$ before and after $5 \mathrm{D}$ Squame applications. a Comparison of melanin/erythema index. b SC hydration as determined by measuring SC capacitance. c Skin surface $\mathrm{pH}$. d Basal permeability barrier function.

PH905 probe immediately after 5 consecutive D-Squame applications. The barrier recovery rate was assessed at $5 \mathrm{~h}$ after barrier perturbation by repeated D-Squame applications [56]. For the SC integrity assay, the TEWL was measured by a TM300 probe after each D-Squame application [51, 57]. All subjects rested at 24$26^{\circ} \mathrm{C}$, with a relative humidity of $50-55 \%$, for $30 \mathrm{~min}$ before measurements were taken. All studies were completed between January and May 2009 (i.e. late winter and spring in northern China).

\section{Statistics}

Data are expressed as means \pm SEM. The GraphPad Prism 4 software was used for all statistical analyses. The paired twotailed Student $t$ test was used to determine the significance for the skin surface $\mathrm{pH}$ before and after tape stripping. The unpaired two-tailed Student t test with Welch's correction was used to assess the significance between vitiligo-involved and contralateral uninvolved sites for other parameters.

This study was performed under human research protocols that were approved by the Human Research Subcommittee of the Dalian Skin Disease Hospital (DSDH122008).

Barrier Recovery Is Delayed in Vitiligo

\section{Results}

\section{Basal SC Biophysical Properties}

Since the primary clinical feature of vitiligo is skin depigmentation, we first quantified the pigmentation in the vitiligo lesions. As seen in figure 1a, the skin melanin index was significantly lower in vitiligo-involved sites than in uninvolved sites (melanin index: $60.93 \pm 4.95$ vs. $203.20 \pm 11.64 ; \mathrm{t}=11.24 ; \mathrm{p}<0.0001)$. In addition, the erythema index was also significantly lower in vitiligoinvolved sites than in uninvolved sites (erythema index: $235.50 \pm 19.79$ vs. $329.00 \pm 13.86 ; t=3.872 ; \mathrm{p}<0.0003)$. These results demonstrate that both melanin and erythema indexes decreased in vitiligo-involved sites.

We next assessed SC hydration, determined by measuring SC capacitance. As seen in figure $1 \mathrm{~b}, \mathrm{SC}$ hydration was significantly diminished in vitiligo-involved sites as 


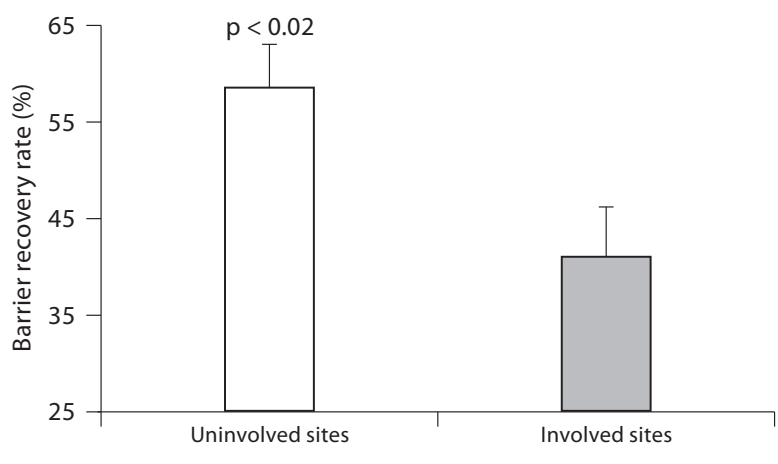

Fig. 2. Comparison of barrier recovery rate between vitiligo-involved and uninvolved sites. Barrier perturbation was achieved by repeated D-Squame applications. The TEWL was measured at involved and contralateral uninvolved sites immediately and $5 \mathrm{~h}$ after barrier disruption. The unpaired two-tailed Student t test with Welch's correction was used to determine significance.

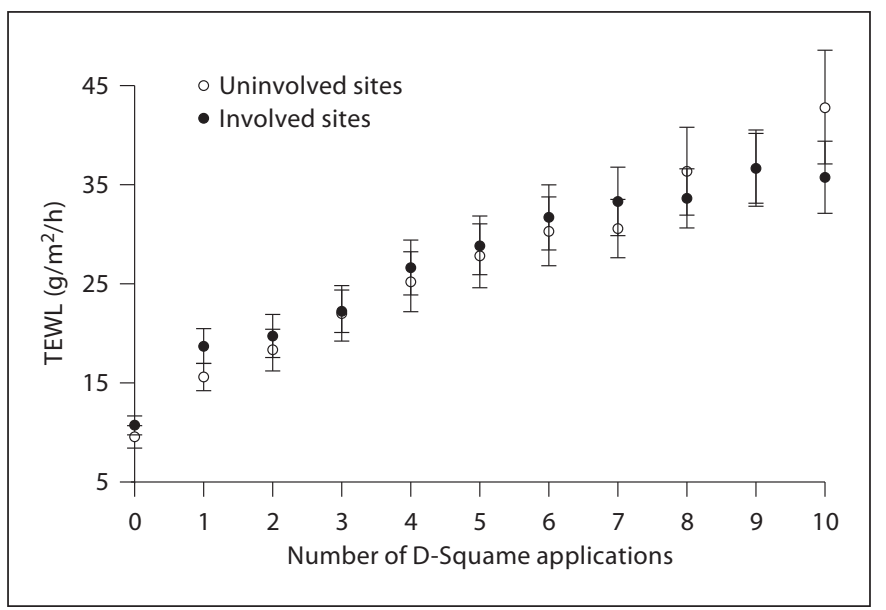

Fig. 3. Comparison of SC integrity between vitiligo-involved and uninvolved sites. The TEWL was measured at vitiligo-involved and contralateral uninvolved sites at baseline and immediately after each D-Squame application. The unpaired two-tailed Student $t$ test with Welch's correction was used to determine significances between vitiligo-involved and contralateral uninvolved sites.

compared with contralateral uninvolved sites (capacitance: $94.67 \pm 2.26$ vs. $116.70 \pm 3.15 ; \mathrm{t}=5.684 ; \mathrm{p}<$ $0.0001)$.

Since skin pigmentation affects the skin surface $\mathrm{pH}$ $[12,15,29]$, we next determined if there was a difference in skin surface $\mathrm{pH}$ between vitiligo-involved and contra- lateral uninvolved sites. As seen in figure 1c, we observed no significant differences in basal skin surface $\mathrm{pH}$ between vitiligo-involved and contralateral uninvolved sites. However, the skin surface $\mathrm{pH}$ in vitiligo-involved sites increased significantly after $5 \mathrm{D}$-Squame applications $(\mathrm{pH} 5.55 \pm 0.079$ vs. $5.67 \pm 0.057 ; \mathrm{t}=3.597 ; \mathrm{p}<$ 0.002 ), whereas in uninvolved sites, it was not elevated significantly following 5 D-Squame applications ( $\mathrm{pH} 5.55$ \pm 0.059 vs. $5.63 \pm 0.047 ; \mathrm{t}=1.958$; not significant).

\section{Epidermal Permeability Barrier Function}

The present study demonstrated that the basal TEWL in vitiligo-involved sites did not differ significantly from that in uninvolved sites $(10.71 \pm 0.94$ vs. $9.57 \pm 1.10$ $\mathrm{g} / \mathrm{m}^{2} / \mathrm{h} ; \mathrm{t}=0.789$; not significant) (fig. 1d). However, barrier recovery was significantly delayed in vitiligo-involved sites in comparison with contralateral uninvolved sites $(40.83 \pm 5.39$ vs. $58.30 \pm 4.71 \% ; \mathrm{t}=2.441 ; \mathrm{p}<0.02)$ (fig. 2). These results suggest that an alteration in epidermal permeability barrier homeostasis occurs in vitiligoinvolved sites.

\section{SC Integrity}

As shown in figure 3, there was no difference in SC integrity between vitiligo-involved and contralateral uninvolved sites following up to $10 \mathrm{D}$-Squame applications. This result indicates that melanin deficiency does not significantly alter SC integrity in vitiligo.

\section{Discussion}

Melanocytes have been thought to function primarily as melanin producers, to generate a natural protectant against UV damage. Although studies demonstrated that photodamage is reduced in vitiligo skin [58], highly pigmented skin requires more UV radiation than lightly pigmented skin to produce erythema [59]. Melanin content negatively correlates with the amount of DNA damage induced by UV radiation [60-63]. The ratio of the minimum erythema dose between skin type V (darkly pigmented) and skin types I/II (lightly pigmented) is close to the ratio of pigment in these skin types [64]. In addition, patients with pigmented skin have a reduced risk for melanoma [65, 66]. Recent studies have demonstrated that SC function is also influenced by pigmentation [42]. Although the present study does not show a difference in basal TEWL between vitiligo-involved and uninvolved sites, we have found that barrier recovery is significantly delayed in vitiligo-involved sites. This finding is consis- 
tent with the reports of others that the barrier recovery rates in type V/VI skin are higher than that in type I/II or II/III skin [12, 14, 42]. Although the mechanisms underlying this abnormal barrier function in vitiligo-involved sites are not clear, it is well known that SC lipids play an important role in permeability barrier homeostasis [67]. Pertinently, darker individuals have more epidermal lipids, especially sterols, than lighter subjects [68]. Moreover, a significantly lower expression of granulocyte-macrophage-colony-stimulating factor is evident in vitiligo-involved sites [21]. Granulocyte-macrophagecolony-stimulating factor stimulates keratinocyte proliferation and VEGF transcription [69, 70], and a deficiency in epidermal VEGF delays barrier recovery [71]. Thus, the alteration in cytokine expression in vitiligo-involved sites could account, at least in part, for the noted alterations in barrier function. Furthermore, epidermal calcium plays a key role in regulating epidermal permeability barrier homeostasis [72]. Keratinocytes from vitiligo-involved sites demonstrate defects in calcium uptake and distribution [73]. Therefore, a defective calcium distribution could represent another mechanism accounting for the abnormal barrier function in vitiligo-involved sites.

Data regarding variations in SC integrity with skin pigmentation are controversial. For example, Berardesca et al. [12] reported that the TEWL was higher in black African-American than in Caucasian skin following 3 or 6 tape strippings, while Reed et al. [14] reported that darker skin (type V/VI) required more tape strippings to generate equivalent barrier dysfunction. In contrast, the present study does not show differences in SC integrity following up to $10 \mathrm{D}$-Squame applications. These differing results may be due to the different study population involved. In the present study, we compared SC integrity in vitiligo-involved and contralateral uninvolved sites on the same subjects, while the other studies compared the integrity between different races, which is known to affect cutaneous function [14, 42, 74].

Regarding the skin surface $\mathrm{pH}$ in darkly and lightly pigmented skin, the results are also inconclusive $[12,15$, 42]. Recent studies have demonstrated that the skin surface $\mathrm{pH}$ is lower in darker skin, which is attributable to accelerated barrier recovery [42]. However, the present study does not reveal any differences in skin surface $\mathrm{pH}$ between vitiligo-involved and contralateral uninvolved sites, which is inconsistent with previous findings in darker and lighter skin $[12,15]$. Again, these distinct findings regarding the skin surface $\mathrm{pH}$ could be due to differences in the studied subjects' race(s) and geographic location. Our results are generated from subjects of the same race living in the same geographic location/environment. In other studies, the subjects were of different races living in different geographic locations/environments [42]. Both the living environment and geographic location have a significant impact on cutaneous function including SC properties [75-78].

Taken together, the results from the present study further suggest that race and living environment are at least partial determinants of the skin surface $\mathrm{pH}$. Thus, it is worthwhile to note that the subjects enrolled in the present study are of the same race and skin type, and that they live in the same geographic location. In addition, the changes in SC properties were compared between vitiligo-involved and uninvolved sites on the same subjects. These factors were able to minimize any variation imposed by differences in race, environment and/or individuals, in contrast to previous studies [12, 15, 42]

The present study also demonstrates that SC hydration is diminished in vitiligo-involved sites compared with contralateral uninvolved sites. The diminished SC hydration in vitiligo-involved sites might result from defective sweat and sebaceous gland functions, which are known to influence SC hydration [79, 80]. In addition to sebaceous gland degeneration, sweat gland degeneration has been reported in vitiligo-involved sites [81]. Additionally, a lower ery thema index in vitiligo-involved sites is also evident in the present study. Although the mechanism for this finding is unknown, it is possible that the lower melanin content in vitiligo interferes with erythema measurements since the levels of melanin and erythema can affect each other when measured by a reflectance spectrometer [82].

In summary, in the present study we have demonstrated that a defective permeability barrier function exists in vitiligo-involved sites, and that melanin does not play a crucial role in regulating the skin surface $\mathrm{pH}$ in vitiligo; therefore, in the treatment of vitiligo, attention should be given to improving the barrier function.

\section{Acknowledgments}

This study was partly supported by the National Institutes of Health grant AR 19098. The authors thank Professor Walter M. Holleran (University of California, San Francisco, Calif., USA) for his critical review of the manuscript. 


\section{References}

$\checkmark 1$ Rawlings AV: Ethnic skin types: are there differences in skin structure and function? Int J Cosmet Sci 2006;28:79-93.

-2 Rebora A, Guarrera M: Racial differences in experimental skin infection with Candida albicans. Acta Derm Venereol 1988;68:165168.

- 3 Aramaki J, Kawana S, Effendy I, Happle R, Löffler H: Differences of skin irritation between Japanese and European women. Br J Dermatol 2002;146:1052-1056.

-4 Berardesca E, Maibach HI: Racial differences in sodium lauryl sulphate-induced cutaneous irritation: black and white. Contact Dermatitis 1988; 18:65-70.

5 Berardesca E, Maibach HI: Racial differences in pharmacodynamic response to nicotinates in vivo in human skin: black and white. Acta Derm Venereol 1990;70:63-66.

-6 Grimes P, Edison BL, Green BA, Wildnauer RH: Evaluation of inherent differences between African-American and white skin surface properties using subjective and objective measures. Cutis 2004;73:392-396.

7 Nouveau-Richard S, Yang Z, Mac-Mary S, Li L, Bastien P, Tardy I, Bouillon C, Humbert P, de Lacharrière O: Skin ageing: a comparison between Chinese and European populations - a pilot study. J Dermatol Sci 2005;40: 187-193.

-8 Diridollou S, de Rigal J, Querleux B, Leroy F, Holloway Barbosa V: Comparative study of the hydration of the stratum corneum between four ethnic groups: influence of age. Int J Dermatol 2007;46(suppl 1):11-14

-9 Johnson LC, Corah NL: Racial differences in skin resistance. Science 1963;139:766-767.

10 Wilson D, Berardesca E, Maibach HI: In vitro transepidermal water loss: differences between black and white human skin. $\mathrm{Br} \mathrm{J}$ Dermatol 1988;119:647-652.

- 11 Kompaore F, Marty JP, Dupont C: In vivo evaluation of the stratum corneum barrier function in Blacks, Caucasians and Asians with two noninvasive methods. Skin Pharmacol 1993;6:200-207.

12 Berardesca E, Pirot F, Singh M, Maibach H: Differences in stratum corneum $\mathrm{pH}$ gradient when comparing white Caucasian and black African-American skin. Br J Dermatol 1998; 139:855-857.

13 Singh J, Gross M, Sage B, Davis HT, Maibach HI: Effect of saline iontophoresis on skin barrier function and cutaneous irritation in four ethnic groups. Food Chem Toxicol 2000;38:717-726.

14 Reed JT, Ghadially R, Elias PM: Skin type, but neither race nor gender, influence epidermal permeability barrier function. Arch Dermatol 1995;131:1134-1138.
15 Fotoh C, Elkhyat A, Mac S, Sainthillier JM, Humbert P: Cutaneous differences between Black, African or Caribbean mixed-race and Caucasian women: biometrological approach of the hydrolipidic film. Skin Res Technol 2008;14:327-335.

16 Badri AM, Todd PM, Garioch JJ, Gudgeon JE, Stewart DG, Goudie RB: An immunohistological study of cutaneous lymphocytes in vitiligo. J Pathol 1993;170:149-155.

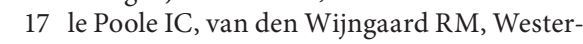
hof W, Das PK: Presence of T cells and macrophages in inflammatory vitiligo skin parallels melanocyte disappearance. Am J Pathol 1996;148:1219-1228.

18 Halder RM, Walters CS, Johnson BA, Chakrabarti SG, Kenney JA Jr: Aberrations in T lymphocytes and natural killer cells in vitiligo: a flow cytometric study. J Am Acad Dermatol 1986;14:733-737.

19 Hann SK, Park YK, Chung KY, Kim HI, Im S, Won JH: Peripheral blood lymphocyte imbalance in Koreans with active vitiligo. Int J Dermatol 1993;32:286-289.

$20 \mathrm{Tu}$ CX, Gu JS, Lin XR: Increased interleukin- 6 and granulocyte-macrophage colony stimulating factor levels in the sera of patients with non-segmental vitiligo. J Dermatol Sci 2003;31:73-78.

21 Moretti S, Spallanzani A, Amato L, Hautmann G, Gallerani I, Fabiani M, Fabbri P: New insights into the pathogenesis of vitiligo: imbalance of epidermal cytokines at sites of lesions. Pigment Cell Res 2002;15:87-92.

22 Moretti S, Fabbri P, Baroni G, Berti S, Bani D, Berti E, Nassini R, Lotti T, Massi D: Keratinocyte dysfunction in vitiligo epidermis: cytokine microenvironment and correlation to keratinocyte apoptosis. Histol Histopathol 2009;24:849-857.

23 Stinco G, Piccirillo F, Forcione M, Valent F, Patrone P: An open randomized study to compare narrow-band UVB, topical pimecrolimus and topical tacrolimus in the treatment of vitiligo. Eur J Dermatol 2009; 19:588-593.

24 Berti S, Buggiani G, Lotti T: Use of tacrolimus ointment in vitiligo alone or in combination therapy. Skin Therapy Lett 2009;14: 5-7.

25 Silverberg NB, Lin P, Travis L, Farley-Li J, Mancini AJ, Wagner AM, Chamlin SL, Paller AS: Tacrolimus ointment promotes repigmentation of vitiligo in children: a review of 57 cases. J Am Acad Dermatol 2004;51: $760-766$.

26 Gowda S, Tillman DK, Fitzpatrick JE, Gaspari AA, Goldenberg G: Imiquimod-induced vitiligo after treatment of nodular basal cell carcinoma. J Cutan Pathol 2009;36: 878-881.

27 Serrão VV, Páris FR, Feio AB: Genital vitiligo-like depigmentation following use of imiquimod 5\% cream. Eur J Dermatol 2008; 18 . 342-343.
28 Jacob SE, Blyumin M: Vitiligo-like hypopigmentation with poliosis following treatment of superficial basal cell carcinoma with imiquimod. Dermatol Surg 2008;34:844-845.

-29 Brown T, Zirvi M, Cotsarelis G, Gelfand JM: Vitiligo-like hypopigmentation associated with imiquimod treatment of genital warts. J Am Acad Dermatol 2005;52:715-716.

- 30 Ardigo M, Malizewsky I, Dell'anna ML, Berardesca E, Picardo M: Preliminary evaluation of vitiligo using in vivo reflectance confocal microscopy. J Eur Acad Dermatol Venereol 2007;21:1344-1350.

31 Gibbs S, Murli S, de Boer G, Mulder A, Mommaas AM, Ponec M: Melanosome capping of keratinocytes in pigmented reconstructed epidermis: effect of ultraviolet radiation and 3-isobutyl-1-methyl-xanthine on melanogenesis. Pigment Cell Res 2000;13:458-466.

- 32 Kobayashi N, Nakagawa A, Muramatsu T, Yamashina Y, Shirai T, Hashimoto MW, Ishigaki Y, Ohnishi T, Mori T: Supranuclear melanin caps reduce ultraviolet-induced DNA photoproducts in human epidermis. J Invest Dermatol 1998;110:806-810.

33 Kobayashi N, Muramatsu T, Yamashina Y, Shirai T, Ohnishi T, Mori T: Melanin reduces ultraviolet-induced DNA damage formation and killing rate in cultured human melanoma cells. J Invest Dermatol 1993;101:685-689.

- 34 Mohagheghpour N, Waleh N, Garger SJ, Dousman L, Grill LK, Tusé D: Synthetic melanin suppresses production of proinflammatory cytokines. Cell Immunol 2000;199: 25-36.

35 El-Obeid A, Al-Harbi S, Al-Jomah N, Hassib A: Herbal melanin modulates tumor necrosis factor alpha (TNF-alpha), interleukin-6 (IL-6) and vascular endothelial growth factor (VEGF) production. Phytomedicine 2006;13:324-333.

36 Montefiori DC, Modliszewski A, Shaff DI, Zhou J: Inhibition of human immunodeficiency virus type 1 replication and cytopathicity by synthetic soluble catecholamine melanins in vitro. Biochem Biophys Res Commun 1990;168:200-205.

37 Montefiori DC, Zhou JY: Selective antiviral activity of synthetic soluble L-tyrosine and L-dopa melanins against human immunodeficiency virus in vitro. Antiviral Res 1991; 15:11-25.

38 Sidibe S, Saal F, Rhodes-Feuillette A, Lagaye S, Pelicano L, Canivet M, Peries J, Dianoux L: Effects of serotonin and melanin on in vitro HIV-1 infection. J Biol Regul Homeost Agents 1996;10:19-24.

- 39 Behne MJ, Meyer JW, Hanson KM, Barry NP, Murata S, Crumrine D, Clegg RW, Gratton E, Holleran WM, Elias PM, Mauro TM: NHE1 regulates the stratum corneum permeability barrier homeostasis: microenvironment acidification assessed with fluorescence lifetime imaging. J Biol Chem 2002; 277:47399-47406. 
40 Smith DR, Spaulding DT, Glenn HM, Fuller BB: The relationship between $\mathrm{Na}^{+} / \mathrm{H}^{+}$exchanger expression and tyrosinase activity in human melanocytes. Exp Cell Res 2004; 298:521-534.

41 Ancans J, Tobin DJ, Hoogduijn MJ, Smit NP, Wakamatsu K, Thody AJ: Melanosomal pH controls rate of melanogenesis, eumelanin/ phaeomelanin ratio and melanosome maturation in melanocytes and melanoma cells. Exp Cell Res 2001;268:26-35.

-42 Gunathilake R, Schurer NY, Shoo BA, Celli A, Hachem JP, Crumrine D, Sirimanna G, Feingold KR, Mauro TM, Elias PM: pH-regulated mechanisms account for pigmenttype differences in epidermal barrier function. J Invest Dermatol 2009;129:1719-1729.

43 Bondanza S, Maurelli R, Paterna P, Migliore E, Giacomo FD, Primavera G, Paionni E, Dellambra E, Guerra L: Keratinocyte cultures from involved skin in vitiligo patients show an impaired in vitro behaviour. Pigment Cell Res 2007;20:288-300.

44 Lee AY, Kim NH, Choi WI, Youm YH: Less keratinocyte-derived factors related to more keratinocyte apoptosis in depigmented than normally pigmented suction-blistered epidermis may cause passive melanocyte death in vitiligo. J Invest Dermatol 2005;124:976983.

45 Lee AY, Youm YH, Kim NH, Yang H, Choi WI: Keratinocytes in the depigmented epidermis of vitiligo are more vulnerable to trauma (suction) than keratinocytes in the normally pigmented epidermis, resulting in their apoptosis. Br J Dermatol 2004;151:9951003.

46 Gniadecka M, Wulf HC, Mortensen NN, Poulsen T: Photoprotection in vitiligo and normal skin: a quantitative assessment of the role of stratum corneum, viable epidermis and pigmentation. Acta Derm Venereol 1996;76:429-432.

- 47 Ye J, Garg A, Calhoun C, Feingold KR, Elias PM, Ghadially R: Alterations in cytokine regulation in aged epidermis: implications for permeability barrier homeostasis and inflammation. 1. IL-1 gene family. Exp Dermatol 2002;11:209-216.

48 Barland CO, Zettersten E, Brown BS, Ye J, Elias PM, Ghadially R: Imiquimod-induced interleukin-1 $\alpha$ stimulation improves barrier homeostasis in aged murine epidermis. J Invest Dermatol 2004;122:330-336.

49 Jiang YJ, Lu B, Crumrine D, Man MQ, Elias PM, Feingold KR: IL-1 $\alpha$ accelerates stratum corneum formation and improves permeability barrier homeostasis during murine fetal development. J Dermatol Sci 2009;54: 88-98.

-50 FluhrJW, Mao-Qiang M, Brown BE, Hachem JP, Moskowitz DG, Demerjian M, Haftek M, Serre G, Crumrine D, Mauro TM, Elias PM, Feingold KR: Functional consequences of a neutral $\mathrm{pH}$ in neonatal rat stratum corneum. J Invest Dermatol 2004;123:140-151.
51 Hachem JP, Crumrine D, Fluhr J, Brown BE, Feingold KR, Elias PM: $\mathrm{pH}$ directly regulates epidermal permeability barrier homeostasis, and stratum corneum integrity/cohesion. J Invest Dermatol 2003;121:345-353.

52 Mauro T, Holleran WM, Grayson S, Gao WN, Man MQ, Kriehuber E, Behne M, Feingold KR, Elias PM: Barrier recovery is impeded at neutral $\mathrm{pH}$, independent of ionic effects: implications for extracellular lipid processing. Arch Dermatol Res 1998;290: 215-222.

53 Holleran WM, Uchida Y, Halkier-Sorensen L, Haratake A, Hara M, Epstein JH, Elias PM: Structural and biochemical basis for the UVB-induced alterations in epidermal barrier function. Photodermatol Photoimmunol Photomed 1997;13:117-128.

54 Phan TA, Halliday GM, Barnetson RS, Damian DL: Melanin differentially protects from the initiation and progression of threshold UV-induced erythema depending on UV waveband. Photodermatol Photoimmunol Photomed 2006;22:174-180.

55 Man MQ, Xin SJ, Song SP, Cho SY, Zhang XJ, Tu CX, Feingold KR, Elias PM: Variation of skin surface $\mathrm{pH}$, sebum content, and stratum corneum hydration with age and gender in a large Chinese population. Skin Pharmacol Physiol 2009;22:190-199.

56 Man MQ, Barish GD, Schmuth M, Crumrine D, Barak Y, Chang S, Jiang Y, Evans RM, Elias PM, Feingold KR: Deficiency of PPARbeta/delta in the epidermis results in defective cutaneous permeability barrier homeostasis and increased inflammation. J Invest Dermatol 2008;128:370-377.

57 Hachem JP, Man MQ, Crumrine D, Uchida Y, Brown BE, Rogiers V, Roseeuw D, Feingold KR, Elias PM: Sustained serine proteases activity by prolonged increase in $\mathrm{pH}$ leads to degradation of lipid processing enzymes and profound alterations of barrier function and stratum corneum integrity. J Invest Dermatol 2005;125:510-520.

58 Schallreuter KU, Tobin DJ, Panske A: Decreased photodamage and low incidence of non-melanoma skin cancer in 136 sun-exposed Caucasian patients with vitiligo. Dermatology 2002;204:194-201.

59 Kaidbey KH, Agin PP, Sayre RM, Kligman AM: Photoprotection by melanin: a comparison of black and Caucasian skin. J Am Acad Dermatol 1979;1:249-260.

60 Tadokoro T, Kobayashi N, Zmudzka BZ, Ito S, Wakamatsu K, Yamaguchi Y, Korossy KS, Miller SA, Beer JZ, Hearing VJ: UV-induced DNA damage and melanin content in human skin differing in racial/ethnic origin. FASEB J 2003;17:1177-1179.

61 Herrling T, Jung K, Fuchs J: The role of melanin as protector against free radicals in skin and its role as free radical indicator in hair. Spectrochim Acta A Mol Biomol Spectrosc 2008;69:1429-1435.
62 Yamaguchi Y, Takahashi K, Zmudzka BZ, Kornhauser A, Miller SA, Tadokoro T, Berens W, Beer JZ, Hearing VJ: Human skin responses to $\mathrm{UV}$ radiation: pigment in the upper epidermis protects against DNA damage in the lower epidermis and facilitates apoptosis. FASEB J 2006;20:1486-1488.

63 Phan TA, Halliday GM, Barnetson RS, Damian DL: Melanin differentially protects from the initiation and progression of threshold UV-induced erythema depending on UV waveband. Photodermatol Photoimmunol Photomed 2006;22:174-180.

64 Kollias N, Malallah YH, Al-Ajmi H, Baqer A, Johnson BE, González S: Erythema and melanogenesis action spectra in heavily pigmented individuals as compared to fair-skinned Caucasians. Photodermatol Photoimmunol Photomed 1996;12:183-188.

65 Kato M, Ohgami N, Kawamoto Y, Tsuzuki T, Hossain K, Yanagishita T, Ohshima Y, Tsuboi $\mathrm{H}$, Yamanoshita $\mathrm{O}$, Matsumoto Y, Takahashi M, Nakashima I: Protective effect of hyperpigmented skin on UV-mediated cutaneous cancer development. J Invest Dermatol 2007; 127:1244-1249.

66 Moan J, Dahlback A, Setlow RB: Epidemiological support for a hypothesis for melanoma induction indicating a role for UVA radiation. Photochem Photobiol 1999;70: 243-247.

67 Feingold KR: The outer frontier: the importance of lipid metabolism in the skin. J Lipid Res 2009;50:S417-S422.

68 Reinertson RP, Wheatley VR: Studies on the chemical composition of human epidermal lipids. J Invest Dermatol 1959;32:49-59.

69 Mann A, Breuhahn K, Schirmacher P, Blessing M: Keratinocyte-derived granulocytemacrophage colony stimulating factor accelerates wound healing: stimulation of keratinocyte proliferation, granulation tissue formation, and vascularization. J Invest Dermatol 2001;117:1382-1390.

70 Cianfarani F, Tommasi R, Failla CM, Viviano MT, Annessi G, Papi M, Zambruno G, Odorisio T: Granulocyte/macrophage colony-stimulating factor treatment of human chronic ulcers promotes angiogenesis associated with de novo vascular endothelial growth factor transcription in the ulcer bed. Br J Dermatol 2006;154:34-41.

-71 Elias PM, Arbiser J, Brown BE, Rossiter H, Man MQ, Cerimele F, Crumrine D, Gunathilake R, Choi EH, Uchida Y, Tschachler E, Feingold KR: Epidermal vascular endothelial growth factor production is required for permeability barrier homeostasis, dermal angiogenesis, and the development of epidermal hyperplasia: implications for the pathogenesis of psoriasis. Am J Pathol 2008; 173:689-699.

72 Mao-Qiang M, Mauro T, Bench G, Warren R, Elias PM, Feingold KR: Calcium and potassium inhibit barrier recovery after disruption, independent of the type of insult in hairless mice. Exp Dermatol 1997;6:36-40. 
73 Schallreuter KU, Pittelkow MP: Defective calcium uptake in keratinocyte cell cultures from vitiliginous skin. Arch Dermatol Res 1988;280:137-139.

74 Wesley NO, Maibach HI: Racial (ethnic) differences in skin properties: the objective data. Am J Clin Dermatol 2003;4:843-860.

75 Hillebrand GG, Miyamoto K, Schnell B, Ichihashi M, Shinkura R, Akiba S: Quantitative evaluation of skin condition in an epidemiological survey of females living in northern versus southern Japan. J Dermatol Sci 2001;27:S42-S52.

76 Muñoz-Garcia A, Williams JB: Cutaneous water loss and lipids of the stratum corneum in house sparrows Passer domesticus from arid and mesic environments. J Exp Biol 2005;208:3689-3700
$\$ 77$ Denda M, Sato J, Masuda Y, Tsuchiya T, Koyama J, Kuramoto M, Elias PM, Feingold KR: Exposure to a dry environment enhances epidermal permeability barrier function. J Invest Dermatol 1998;111:858-863.

78 Katagiri C, Sato J, Nomura J, Denda M: Changes in environmental humidity affect the water-holding property of the stratum corneum and its free amino acid content, and the expression of filaggrin in the epidermis of hairless mice. J Dermatol Sci 2003;31: 29-35.

79 Fluhr JW, Mao-Qiang M, Brown BE, Wertz PW, Crumrine D, Sundberg JP, Feingold KR, Elias PM: Glycerol regulates stratum corneum hydration in sebaceous gland-deficient (asebia) mice. J Invest Dermatol 2003;120: 728-737.
80 Choi EH, Man MQ, Wang F, Zhang X, Brown $\mathrm{BE}$, Feingold KR, Elias PM: Is endogenous glycerol a determinant of stratum corneum hydration in humans? J Invest Dermatol 2005;125:288-293.

81 Gokhale BB, Mehta LN: Histopathology of vitiliginous skin. Int J Dermatol 1983;22: 477-480

-82 Takiwaki H, Miyaoka Y, Kohno H, Arase S: Graphic analysis of the relationship between skin colour change and variations in the amounts of melanin and haemoglobin. Skin Res Technol 2002;8:78-83. 